\title{
Impact Assessment of Microgrid in Smart Cities: Indian Perspective
}

\author{
Nawaz Ali Warsi ${ }^{1} \cdot$ Anwar Shahzad Siddiqui $^{1} \cdot$ Sheeraz Kirmani $^{1} \cdot$ Md Sarwar $^{1}$
}

Received: 15 July 2019 / Accepted: 30 October 2019 / Published online: 12 November 2019

(C) Springer Nature Singapore Pte Ltd. 2019

\begin{abstract}
Access to reliable electricity is one of the key enablers of social and economic development. Smart energy and electricity network are one of the key factors in making a city smart; a detailed analysis considering aspects like environmental, energy, economic and societal impacts have to be done for their harmonized inclusion in the smart city design. Increasing energy demand and environmental concerns has led the way for cost effective microgrids with energy storage and backup generation which helps in minimizing energy imbalance, reducing losses and carbon emission, enhancing the overall reliability and resilience of the system. This paper first discusses the main impact of deployment of microgrids in smart cities considering different aspects like societal, economic and environmental. In the later stages of the paper a benefit analysis of microgrids adoption in one of the smart city located in the state of Uttar Pradesh is presented in terms of reliability enhancement and reduction of system losses.
\end{abstract}

Keywords Smart city $\cdot$ Microgrid $\cdot$ Transmission and distribution loss $\cdot$ Aggregate technical and commercial loss $\cdot$ SAIFI $\cdot$ SAIDI

\section{Introduction}

The Economy of the nation depends upon the growth of its cities. In India $63 \%$ of its GDP is contributed by the population living in urban areas, which is expected to further rise to $75 \%$ by 2030 . This is only possible by rapid urbanization i.e. increase in population living in urban areas. The overall development and improvement in the field of physical, institutional, social and economic infrastructure will result in a better quality of life which in turn will attract people and investments in city. This will set a platform for the development of smart cities.

The concept of Smart city is mainly related with the way through which the socioeconomic, environmental and technical systems are expected to evolve the current urban infrastructure to a more sustainable, fair and resilient urban structure [1]. In particular the main features of smart cities in terms of electricity is assured supply of electricity using renewable sources of energy, use of energy efficient techniques in the entire set up i.e. at least $80 \%$ building in the city should be energy efficient. Smartness not only refers to the technological issues but includes the smart integration of all infrastructure

Md Sarwar

sarwaramu@gmail.com

1 Department of Electrical Engineering, Jamia Millia Islamia, New Delhi, India and socioeconomic functions paving way for a desirable future. This desirable future can be attained only by smart use of human, financial and technical resources without neglecting environmental, demographic, social, infrastructural and economic challenges.

One of the key features of smart city in terms of power scenario is smart energy and reliable electricity networks, in fact the two technological dimensions which mainly characterize smart cities are electricity grids and the information and communication network. Smart energy and electricity networks lead to the integration of microgrids in smart cities which not only facilitate the integration of renewable energy sources but also enable new energy related value-added services [2]. In particular the transformation of urban infrastructure to smart city will be mainly driven by the deployment of microgrids. Distribution grids provide indispensable basic service to other infrastructure like water, transportation etc. and the introduction of microgrids with advanced information and communication technologies make them an exemplary guide for implementation of smart cities.

The introduction of information and communication technologies in the traditional grids has changed the dynamics of operation of electricity system facilitating interactions among all stakeholders which resulted in new means for the creation of social welfare and economic values. Microgrids has many positive results in the context of smart city as it provides the capacity to manage vastly distributed generation, enables large quantities of renewable sources in almost each building 
and city spot, provides for the increase in demand and peer to peer exchanges of electricity among end users [3]. However, to incorporate microgrids in smart cities require proper planning and investment. The deficits in any of them will result in deficiencies in power system. The system should be flexible enough for transformation into new smart energy system.

Not the least, microgrids and smart cities are about anticipating situations with efficient forecast of weather conditions and providing real time solution. In order to achieve adequacy and reliability of the highly distributed system detailed planning along with new approach for optimization is required [4]. In comparisons to technical issues whose solutions can be found by existing and foreseeable technologies the main challenges mainly lie in institutional, market and social arrangements that should accompany the deployment of microgrids in smart cities. The implementation of microgrids in smart cities as socio-techno-economic can only be achieved by ensuring retail electricity markets with fair practices, trustworthy management of consumers commercial information and active participation of consumers in the energy market.

Nevertheless, until now, few works have been done regarding challenges in energy systems for the smart cities of the future. The benefits of microgrids project are analyzed in [5]. Microgrid applications and integration of renewable energy systems in smart cities is presented in [6]. In [7], the author provides an insight into the future trends in smart grids, microgrids and smart buildings. However, societal impacts of these future trends were not highlighted.

Apart from providing a number of socio-economic benefits, the microgrid implementation with the distribution network in a smart city is widely performed to ensure reliable electricity supply to the customers or residents of the city. This, in turn, depends upon the robustness of the transmission and distribution (T\&D) network as well as the amount of energy availaible to the Discoms for distribution. With the deficit in energy supply and weak T\&D infrastructure, an attention needs to be given to the reliability enhancement of the distribution network. A detailed reliability analysis of the IEEE RBTS Bus 4 distribution system is carried out in [8], wherein the reliability indices for various load points are evaluated based on various network components failures. However no measure is recommended to increase its reliability. Fortunately, various works are reported in literature to enhance the reliability such as network reconfiguration. One of the widely researched method nowadays, is the integration of various distributed energy sourcses or microgrids to the existing distribution network [9]. The authors have demonstrated the ability of microgrid in implementation in a low voltage distribution network in reducing the interruption time and rate of the power supply. Various reliability indices are evaluated considering generation to load ratios. However, the author considered a small network for the analysis purpose. Microgrid is also implemented in [10] to improve overall system efficiency in a smart city. Different possibilities of the microgrid generation are presented. The author has considered only a household as a load supplied by the solar photovoltaic and wind turbine. In [11], an analytical technique for evaluating the reliability of customers in a microgrid with DERs operated by different operators is presented. The reliability of the load point is decided by the priority of the customers. For a particular load, a case study is presented in [12] for providing a reliable electricity supply. The various factors for unreliable electricity supply are discussed. It demonstrates the benefit of microgrid in offering a sustainable alternative for frequent outages. However the authors did not considered the mixed load available at various load points of the distribution feeder. A similar approach is adopted in [13]. The reliability is assessed for a honeycomb distribution grid. The resilience of the microgrid against contingencies is discussed [14]. This helps in planning the microgrid for optimal operation. In [15], a probabilistic method based on segmentation concept is used for evaluation of the reliability of distribution system with wind-based distribution generation. A series of new metrics for the reliability and economic assessment of microgrids in distribution network is presented in [16]. The range of the proposed metrics includes indices indicating distributed generation and load characteristics in the microgrids, microgrid economic indices, and customer-based reliability indices. However, all these analysis considered a small network for the reliability assessment. The purpose of this paper is to analyze the current health of the T\&D system of Indian cities and how microgrid could be proved as a boon to transform its cities into a smart city. Firstly, the role of the microgrid is assessed based on the socio-economic and environmental benefits. Secondly, its implementation impact in Indian cities is presented based on various parameters related to energy requirement such as energy supply, economy, power loss etc. Finally, a detailed analysis is performed to achieve a robust distribution system with minimal loss and enhanced reliability. The analysis is done for the city of Rampur as losses here is on the higher side. The results of the analysis could be of great help for various stakeholders and policy makers involved.

\section{The Vision of Smart Cities}

There are various definitions of smart cities present in the literature, there is no unique definition of smart city but what is common to majority of these definitions is the stress which is being given upon innovative and forward-looking use of infrastructural systems in order to have a positive effect on climate, environmental, social and economic conditions [9]. Smart city mission is an initiative of Government of India whose main focus is to promote economic growth along with improved quality of life. The core infrastructure elements of 
smart city include assured electricity and water supply, sanitation, robust IT connectivity, public transport etc. The energy system and the city should be flexible enough to adapt to different condition and need. The key features of the power distribution system of smart city should be as follows:

- Reliability- Uninterrupted and quality supply through proper backup

- Smart

- Sustainable

- Expandable

- Low T\&D and AT\&C losses

This vision of smart city requires a holistic perspective in terms of its design and development. The thematic issues in smart cities can be resolved by taking into consideration various concerns and values of a wide range of potential stakeholders. The concept of smart city is nothing but a vision leading to sustainable, inclusive, fair, and resilient urban area. This vision of smart city having a cleaner environment, a decarbonized economy, a cost-effective energy system is achieved by reengineering of present infrastructural systems while taking into consideration other aspects like technical, market, social [17].

Another important criterion to consider regarding path to smartness of city is the availability of common reference framework for the evaluation of impacts caused by the implementation of microgrids and cities [18]. A common reference framework is necessary for having an insight into relative value of technologies and services, comparisons of results and on the basis of this solutions are adjusted, replicated and scaled. In addition, it will pave way for innovation and investment as it will help in pointing the shortcomings of the proposed technologies and services.

\section{Role of Microgrids in Smart City}

Distributed Energy resources are gradually replacing centralized and large-scale generating facilities mainly due to concerns to environment pollutions and more saving in cost with an increase level of production. Distributed Energy resources include microgenerators like diesel generator, fuel cell, photovoltaic panel, wind turbine etc. and energy storage devices like flywheel, supercapacitor, battery etc. High penetration level of Distribution Energy resources in the aging electricity infrastructure demands fundamental and major changes in its hierarchy. Monitoring, controlling and providing real time solutions for large number of Distributed Energy resources are a tedious task [19]. In this context, a viable option to manage large number of distributed Energy Resources is to break it up into smaller Distribution systems. These Smaller Distributed Energy Resources which take full advantage of a multitude of
DERs are known as microgrids and hence they provide a platform for developing distributed power systems.

A microgrid mainly interconnects Distributed Energy Resources and loads within electrically defined boundaries. The benefits of deployment of local renewable energy resources in microgrids are realized through demand side management which responds effectively to the mitigation of environmental pollution and climatic changes. Microgrids provide more flexibility to the operation of power system. The deployment of microgrids in present power system make it more resilient and efficient in terms of power quality, electricity costs and maintaining continuity of power supply to critical loads in case of prolonged outages.

In the context of smart city continuous power supply is one of the key elements in its development. Supplying power to smart city will be a challenging task as it will require strong and smart transmission and distribution systems. Microgrids with integration of advanced technologies act as an exemplary guide for establishment of smart cities. Inclusion of microgrids enables the citizens of smart cities to feed their unused power to the grid which leads to optimum use of energy in smart city. In particular microgrids play a key role in enabling economic value and business opportunities in road to transition to smart cities by facilitating interactions among stakeholders, which in turn results in social welfare and economic values.

\section{Assessing the Societal Impacts of Microgrids in Light of Smart Cities}

The social benefit is an important factor which is considered before the implementation of Microgrids. The societal impacts of microgrids are mainly determined on the basis of systematic approach which considers different assessment criteria like resilience, sustainability, fairness, economic efficiency, social welfare, pollutant levels etc. The societal impacts are categorized as monetizable and non-monetizable impacts. The overall assessment comprises of following analysis [20].

- Economic Analysis- This analysis mainly highlights the monetary gains of deployment of microgrids in smart cities. One of the critical factors resulting in large scale deployment of microgrid in smart city is the huge economic benefits created by it. In the context of smart cities deployment of microgrids resulting in large economic benefits of different stakeholders is due to 1) reduction in purchases of transmission and distribution ancillary services 2) reduction in transmission and distribution losses. 3) provision of sale of excess power i.e. customer act as prosumers.

- Sustainability Analysis- In this analysis all environmental and climate related aspects, including energy consumption, $\mathrm{CO} 2$ emissions, pollutants, waste processes etc. is analyzed. The integration of renewable technologies in 
Fig. 1 Typical structure of a microgrid in smart city microgrids has resulted in reduction of participant exposure to future carb on regulation and cost.

- Technical Analysis- The main objective of this analysis is to highlight the importance of balance management of demand and supply for enhancing the reliability and voltage quality of supply which will result in better quality of energy services. It also highlights challenges related to interconnection of microgrids with main grid, integration of distributed energy resources, energy storage, services related to smart meters and security of data communication.

- Market Analysis- Microgrids through the use of dispersed generation provides value to all ratepayers in the form of enhanced electricity price elasticity. This analysis deals with the impact of microgrids on electricity retail price. It assesses the overall increase in competition between different energy retailers in terms of quality of energy supplied by them.

The final step in the assessment of societal impacts of microgrids in smart cities must take into consideration social factors, institutional factors, technological factors. Social factors are mainly related to concerns, values and interest of society. Institutional factors are mainly concerned with governance and regulatory models. Technological factors mainly deal with reliability, quality and security of supply. A typical structure of microgrid implementation in smart city is shown in Fig.1.

\section{Indian Scenario for Smart City Development}

One of the important features which distinguish smart city from normal cities is its ability to meet its energy demand without any interruption i.e. there is uninterruptible supply of power. This is achieved through surplus power generation as well as through robust power transmission and distribution (T\&D) system. In order to achieve the vision of smart city in India much attention needs to be paid on the ongoing scenario in the power sector of the country.

In most of the Indian states there exists an unbalance between demand and supply of energy which results in discontinuous power supply to the loads or customer of these states. The different state grids of the country are interconnected to form a regional grid as a result the regional grid was demarcated into five regions i.e. north, south, east, west, north eastern region. The region wise (based on grid) peak shortage of power of different states falling under different regions as of February 2019 is shown in Fig. 2 (http://www.cea.nic.in). It can be observed that almost in each region more than two states fall short of required power supply during peak loads. Also, it can be observed that the states in the northern region have more peak supply shortage as compared to the states of other regions of the country.

Another factor which helps in ensuring continuous supply of power is robust $T \& D$ system. The performance of $T \& D$ system and its adequacy to meet the uninterrupted power needs of the cities is assessed in terms of T\&D losses and Aggregate Technical and Commercial (AT\&C) losses which are given as [21]:

$T \& D$ Losses $=\left(1-\frac{E_{b}}{E_{i}}\right) \times 100$

$A T \& C$ Losses $=\left[1-\left(\frac{E_{b}}{E_{i}} \times \frac{A_{C}}{A_{t}}\right)\right] \times 100$

where, $E_{b}$ and $E_{i}$ are the total energy billed and total energy input to the system respectively whereas $A_{c}$ and $A_{t}$ are the 


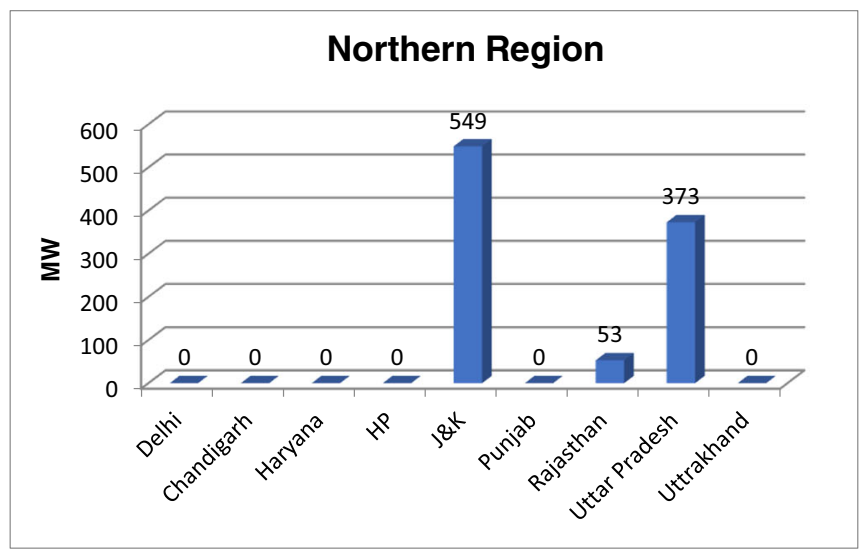

(a) Peak supply shortage of Northern region

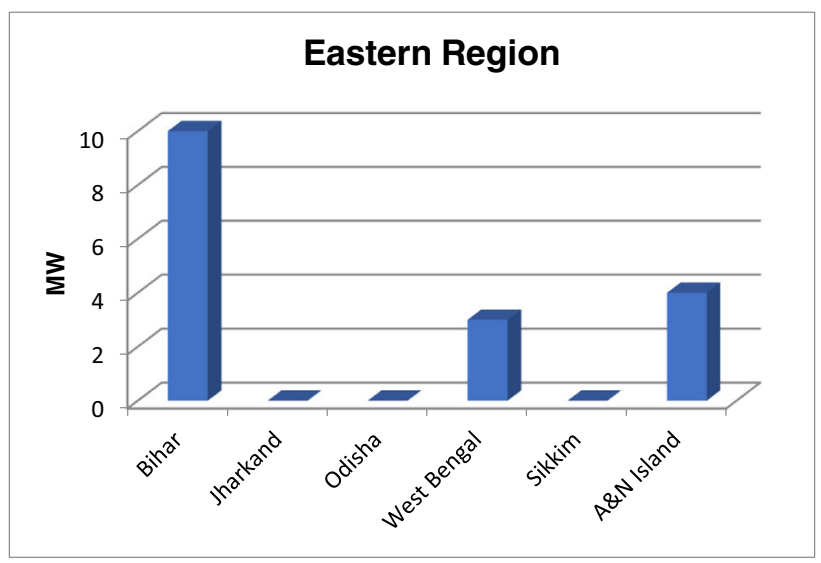

(c) Peak supply shortage of Eastern region

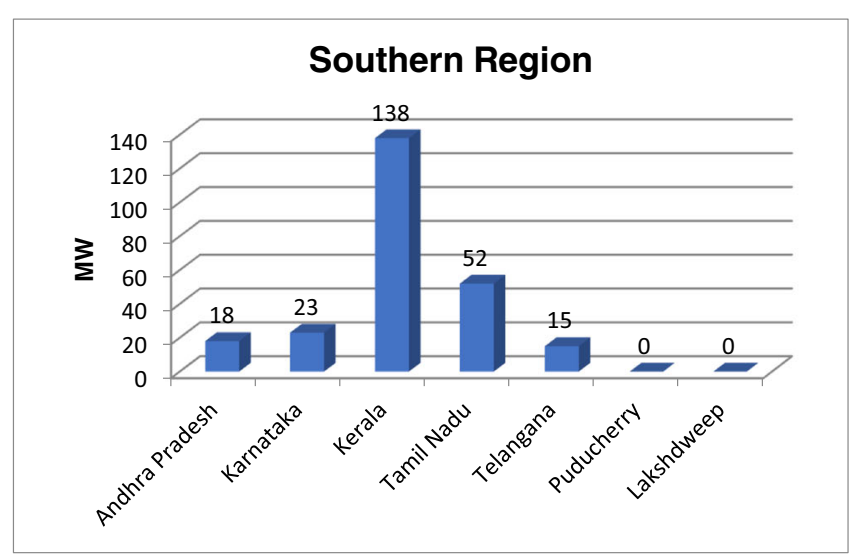

(b) Peak supply shortage of Southern region

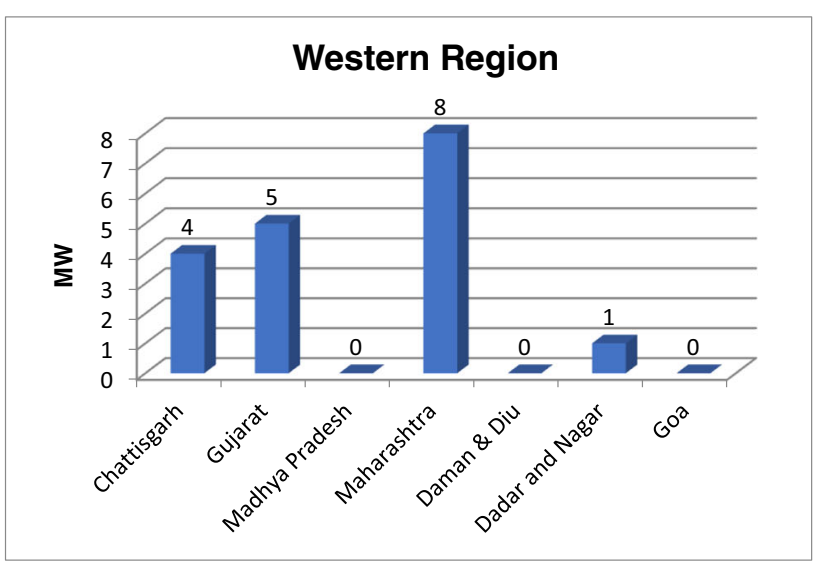

(d) Peak supply shortage of Western region

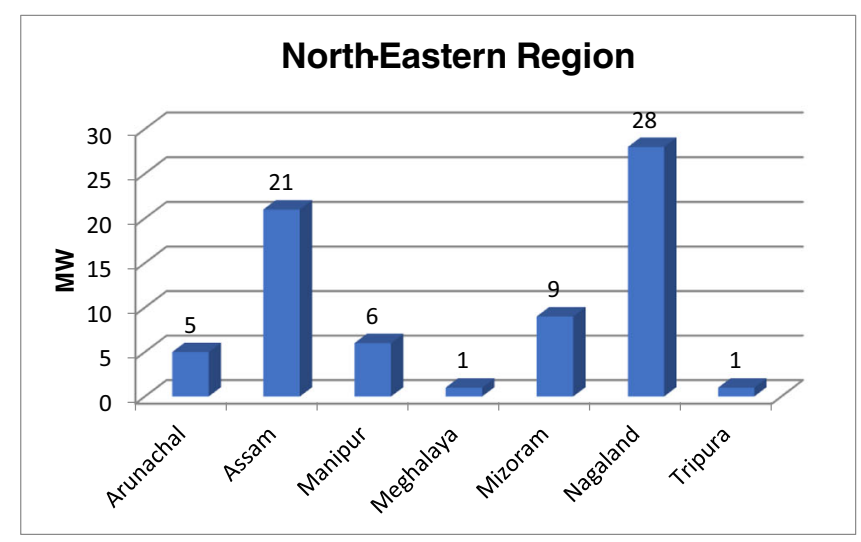

(e) Peak supply shortage of North-Eastern region

Fig. 2 Peak supply shortage of different regions of India. (a). Peak supply shortage of Northern region (b). Peak supply shortage of Southern region (c). Peak supply shortage of Eastern region (d). Peak supply shortage of Western region (e). Peak supply shortage of North-Eastern region

Table 1 Annual average AT\&C losses of India

\begin{tabular}{lllllllllll}
\hline Year & $2007-2008$ & $2008-2009$ & $2009-2010$ & $2010-2011$ & $2011-2012$ & $2012-2013$ & $2013-2014$ & $2014-2015$ & $2015-2016$ & $2018-2019$ \\
\hline AT\&C (\%) & 29.45 & 27.37 & 26.78 & 26.04 & 26.63 & 25.48 & 22.58 & 24.62 & 23.98 & 21.64 \\
\hline
\end{tabular}




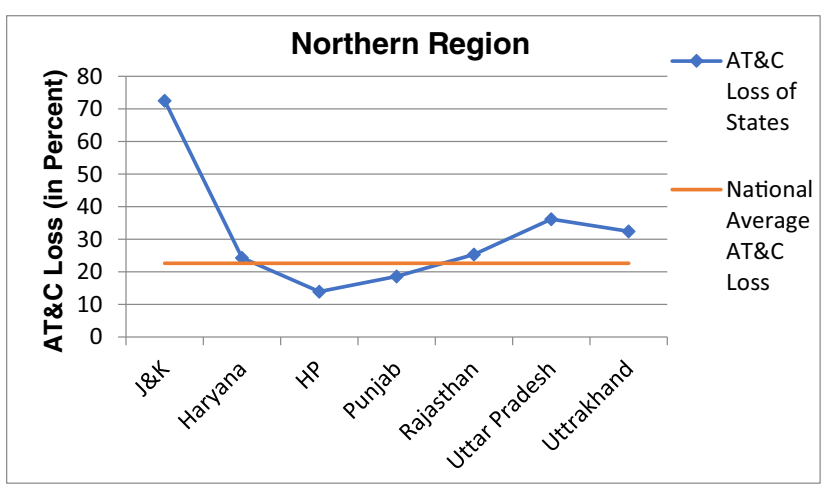

(a) AT\&C lossesof Northern region

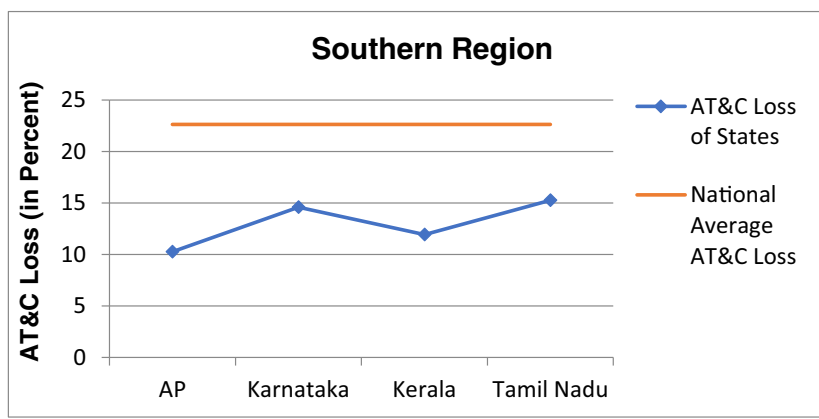

(c) AT\&C losses of Southern region

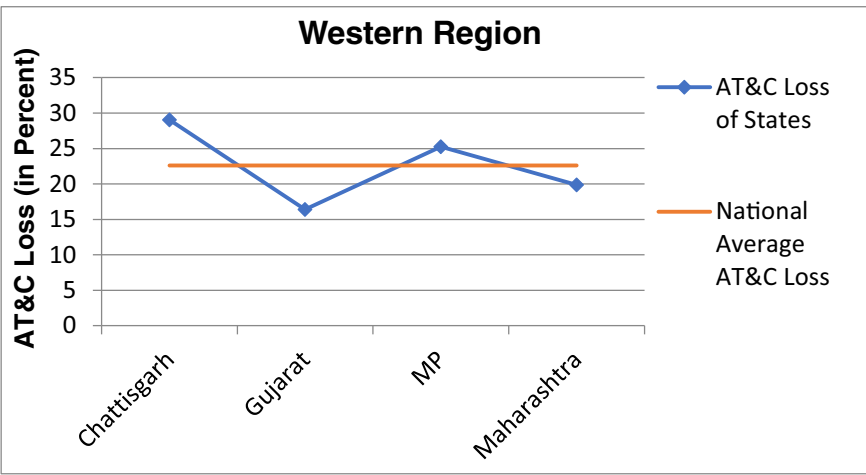

(b) AT\&C losses of Western region

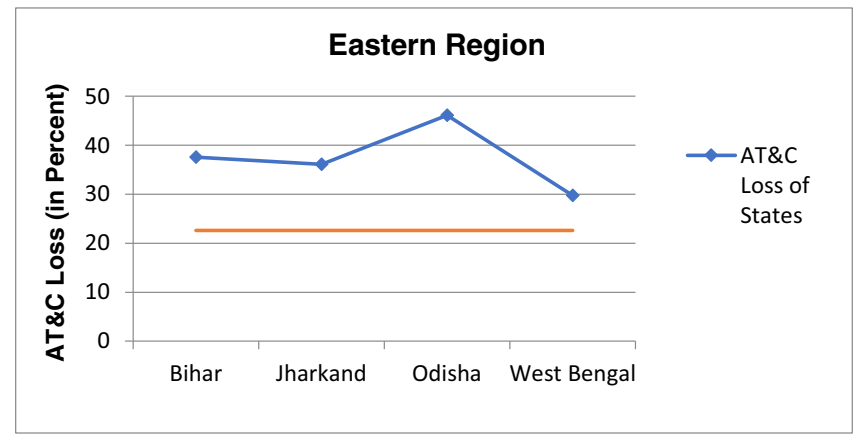

(d) AT\&C losses of Eastern region

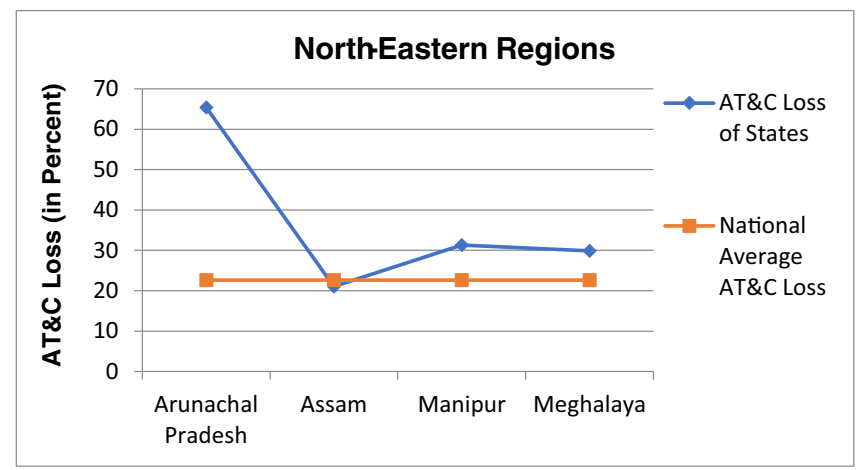

(e) AT\&C lossesof North-Eastern region

Fig. 3 AT\&C losses of different regions of India (a). AT\&C losses of Northern region (b). AT\&C losses of Western region (c). AT\&C losses of Southern region (d). AT\&C losses of Eastern region (e). AT\&C losses of North-Eastern region

total revenue collected and total amount billed by the Discom respectively. The ratio $\left(E_{b} / E_{i}\right)$ is called as the billing efficiency while $\left(A_{c} / A_{t}\right)$ is called as the collection efficiency of the Discoms.

T\&D losses reflect on energy saving which in turn indicate the performance of T\&D systems whereas AT\&C losses reflect on the performance and benefit of the Discoms. The condition of the distribution system is often measured in terms of AT\&C losses. As of March 2019, the AT\&C loss is $21.64 \%$ (https://npp.gov.in). Table 1 shows the national average of $\mathrm{AT} \& \mathrm{C}$ losses in different years. Initially, these losses are very high due to the inefficient resource management and planning, insufficient investment, low plant load factor, high power theft, incorrect or non-billing etc. However with the various measures taken by the government of India through several schemes such as Feeder Separation Program (FSP), Accelerated Power Development and Reforms Program (APDRP), Restructured Accelerated Power Development and Reforms Program (R-APDRP), Integrated Power Development Scheme (IPDS) etc. with the aim of strengthening the T\&D system and curbing the high AT\&C, the losses decreased over the years. Although, a decreasing trend is achieved, these losses are still considerably on the higher side. Therefore, strong measures must be taken in order to bring these losses to a considerably lower value which would result in a robust $\mathrm{T} \& \mathrm{D}$ system. 
Fig. 4 Percentage peak supply shortage of different states of India

\section{Percentage Supply Peak Shortage in Different States}

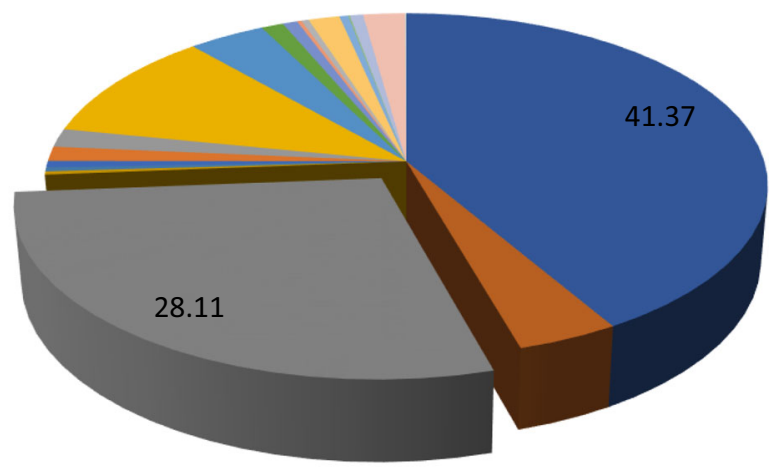

a J\&

Rajasthan

- Uttar Pradesh

- Chattisgarh

- Gujarat

- Madhya Pradesh

- Maharashtra

Andhra Pradesh

Karnataka

- Kerala

- Tamil Nadu

- Telangana

Bihar

- West Bengal

Arunachal

Assam

- Manipur

Meghalaya

Mizoram

Nagaland

Tripura
A deeper insight into these losses for different Indian states as of March 2019 can be observed from Fig.3 which shows that more than half of the Indian states have losses in their distribution system above the national average of $21.64 \%$ (https://npp.gov.in). Such high value of losses in the distribution system is accounted to high rate of electricity pilferages and technical losses in the system. The high AT\&C losses act as a major hindrance in the road to transition to smart city. Therefore these losses must be minimized to achieve the objectives of smart city.

Besides the above discussed factors, average power purchase cost (APPC) is another parameter which directly impacts the electricity cost. APPC is the average cost incurred by the Discoms for purchasing power from conventional sources of energy. It excludes the cost of power procurement from the renewable sources of energy as well as transmission charges. High APPC results in high tariff for the consumers and thereby increase the revenue gap for the Discoms. Thus, there is a need to lower the APPC so that the benefits of smart city can be availed by every citizen at lower electricity cost.

Microgrid implementation plays an important role in achieving the objectives of the smart city. It provides a robust means to deal with the demerits of above-mentioned factors. The reasons to adopt microgrids as a feasible solution is based on their ability to meet the diverse needs of end users for higher quality power supplies besides this it also enhances the reliability of the system and reduces the cost of electricity. In this paper, we consider a microgrid implementation which would be highly conducive and helpful in upgradation of shortlisted cities to smart city.

The government of India has shortlisted 100 cities from its different states for transforming them into smart cities. The highest number of city is shortlisted from the state of Uttar Pradesh followed by Tamil Nadu and Maharashtra which has
Fig. 5 Percentage AT\&C losses of major states of India

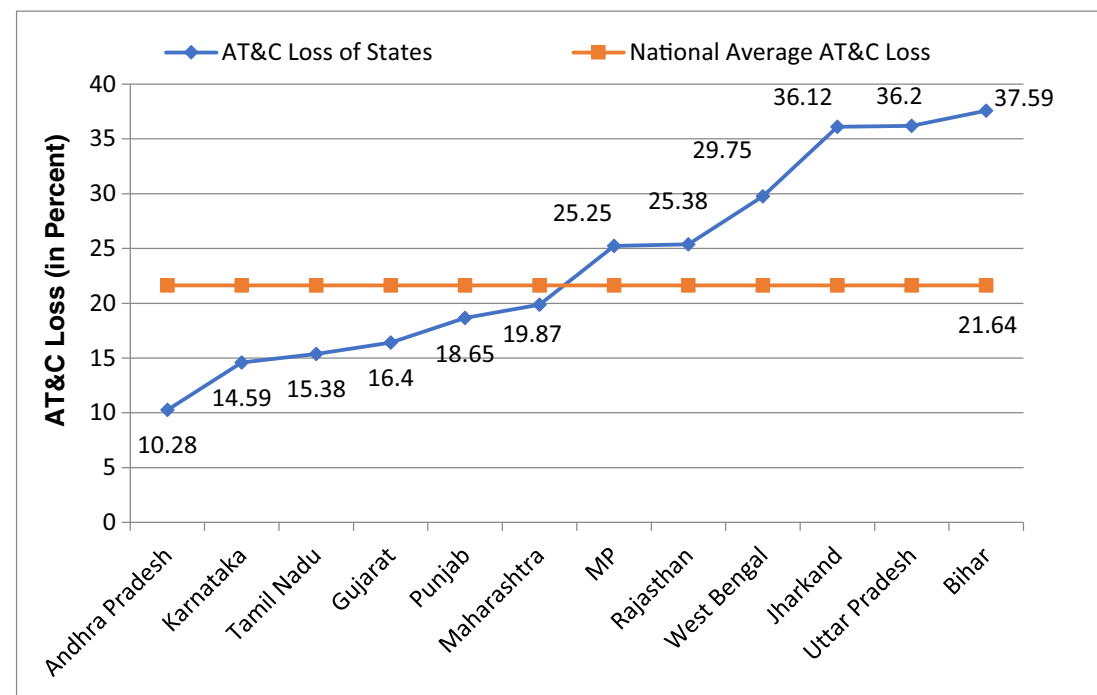


Fig. 6 APPC of major states of India

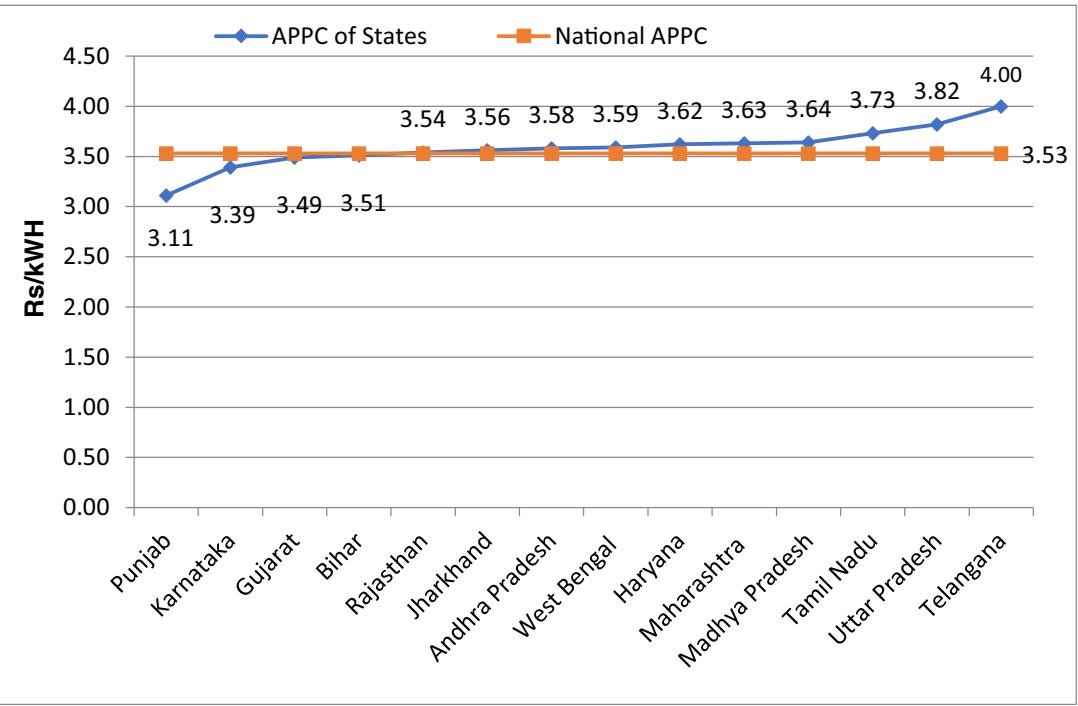

11 and 10 number of cities respectively (http://smartcities.gov. in/). These cities will be declared as a smart city only by ensuring continuous electricity supply, low T\&D/AT\&C losses, cheap electricity, and minimum number and duration of outages. However, the detailed analysis of these shortlisted cities in terms of power scenario is not very encouraging. From Fig.2 and Fig. 3, it can be stated that most of the states have unfavourable values of these parameters which further complicates the job of transforming them into smart city. Since Uttar Pradesh has the highest number of allotted smart

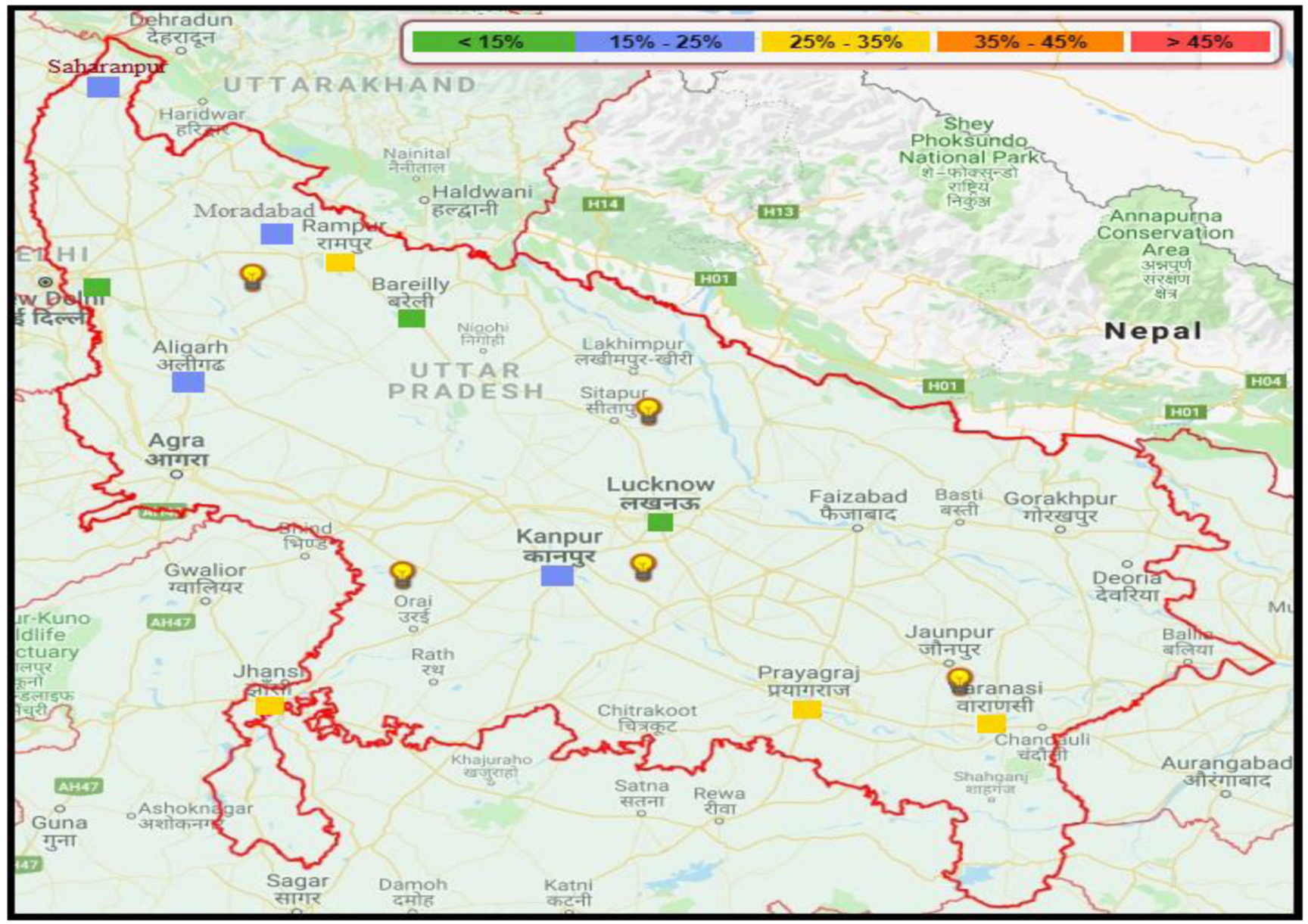

Fig. 7 Location of smart cities of Uttar Pradesh 
Table 2 AT\&C losses of different smart cities of Uttar Pradesh

\begin{tabular}{lllll}
\hline S. No. & Name of City & AT\&C Loss & Average Duration of Power Cuts (hrs/month) & Average No. of Power Cuts (times/month) \\
\hline 1 & Lucknow & 13.91 & 2.5 & 3.1 \\
2 & Kanpur & 15.09 & Not Available & Not Available \\
3 & Varanasi & 29.34 & 0.58 & 2.5 \\
4 & Aligarh & 24.58 & 7.13 & 8.2 \\
5 & Moradabad & 16.6 & 2.07 & 3.2 \\
6 & Saharanpur & 19.71 & 1.57 & 4.4 \\
7 & Bareily & 11.69 & 2.23 & 2.7 \\
8 & Jhansi & 25.31 & 4.36 & 5.3 \\
9 & Allahabad & 39.47 & 0.56 & 3 \\
10 & Ghaziabad & 8.05 & 1.59 & 4 \\
11 & Rampur & 40.59 & 2.49 & 3.5 \\
12 & Agra & Not Available & Not Available & Not Available \\
\hline
\end{tabular}

cities, therefore in this paper performance analysis of the shortlisted cities based on percentage supply peak shortage, AT\&C losses and APPC is done and compared with other states of the country.

Figure 4 shows that as of February 2019, Uttar Pradesh has the highest percentage of peak shortage of supply after Jammu $\&$ Kashmir in the entire region of the country. Similarly, on comparison with other states in terms of AT\&C losses, it can be inferred from Fig. 5 that Uttar pradesh has the highest value of these losses as compared to the other major states of the country having comparable terrain, area, population etc. such as Madhya Pradesh, Rajasthan, Gujarat etc. except Bihar. Even Tamil Nadu, having the highest number of smart cities allotted after Uttar Pradesh, has very low value of AT\&C loss. Furthermore, Uttar Pradesh has the highest APPC among the states as shown in Fig. 6. It has APPC of Rs 3.82/kWH which is $8.22 \%$ higher than the national average of Rs $3.53 / \mathrm{kWH}$ as on September 2018 (https://npp.gov.in).

The AT\&C losses and APPC values lie on higher side for the state of Uttar Pradesh and it is one of the major hindrances in the road to transition to smart city.
Figure 7 shows the strategic location of these shortlisted cities on the map of Uttar Pradesh. The values of the AT\&C loss as on March 2019 can be observed from Table 2 (https://npp.gov.in). Two cities, Allahabad and Rampur has AT\&C loss greater than the average loss of the state of $36.2 \%$ whereas most of the cities has higher values than the national average of $21.64 \%$ as shown in Fig. 8. Table 2 also shows the average duration of power cuts and number of power cuts in a month in these cities. It is observed that the average duration of power cut and average number of power cuts in these cities are $2.5 \mathrm{~h} /$ month and 3.99 times/month which is very high and unfavourable by standards of smart city. Also, the high value of power loss and power cuts results in revenue loss of the Discoms. The above analysis highlights the ill health of the transmission and distribution system of the state. The transmission and distribution infrastructure of the state requires immediate maintenance and upgradation so that the above mentioned parameters lie on much lower side of the scale which in turn can help in transforming its cities into a smart city.
Fig. 8 Percentage AT\&C losses comparison of smart cities of Uttar Pradesh with state average and national average

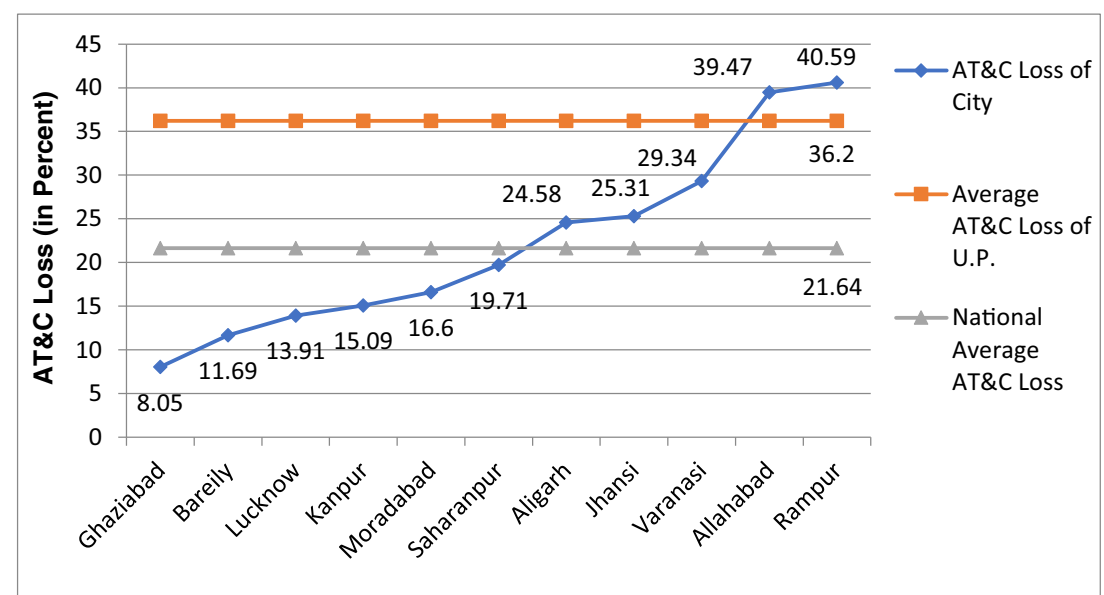


Table 3 Present scenario of smart cities and microgrid implementation benefits

\begin{tabular}{|c|c|c|}
\hline Parameters & Assessment of the present condition of city in terms of each parameters & Microgrid implementation benefits \\
\hline $\begin{array}{l}\text { Energy } \\
\quad \text { Source }\end{array}$ & $\begin{array}{l}\text { - The city is generally reliant on the Power supply through the grid generated within state } \\
\text { and outside of the state. } \\
\text { - Very few amount of demands are met through renewable sources. }\end{array}$ & $\begin{array}{l}\text { - Development of Microgrid to incorporate renewable } \\
\text { sources of energy. } \\
\text { - The cities have good potential of installing rooftop } \\
\text { solar plants which can be integrated to mcirogrid. }\end{array}$ \\
\hline $\begin{array}{l}\text { Energy } \\
\quad \text { Supply }\end{array}$ & $\begin{array}{l}\text { - Electricity is available for most part of the day, but some areas are not well served. } \\
\text { - Energy deficit during peak demands } \\
\text { - Power cut as high as } 7.13 \mathrm{~h} / \text { month. }\end{array}$ & $\begin{array}{l}\text { - Installation of microgrids to maintain continuity of } \\
\text { supply. } \\
\text { - Microgrid helps in decreasing the energy } \\
\text { supply-demand gap thereby decreasing the duration } \\
\text { of power cuts. }\end{array}$ \\
\hline $\begin{array}{l}\text { Reliability \& } \\
\text { Security }\end{array}$ & $\begin{array}{l}\text { - Most of the transmission and distribution lines of the city are not well maintained as a } \\
\text { result they don't withstand or quickly recover from damage. } \\
\text { - Frequent power outages occur in city. }\end{array}$ & $\begin{array}{l}\text { - Microgrids will make system more redundant and } \\
\text { resilient to disturbances. } \\
\text { - Microgrids will ensure grid independence to } \\
\text { individual end users. } \\
\text { - Enabling grid modernization and integration by } \\
\text { using technologies of microgrids. }\end{array}$ \\
\hline Economy & $\begin{array}{l}\text { - Per unit cost of electricity is very high in the city. } \\
\text { - High Losses as well as high APPC contributes to the high cost of electricity }\end{array}$ & $\begin{array}{l}\text { - Installations of microgrids will substantially cut the } \\
\text { cost of electricity. } \\
\text { - Customers can act as prosumers in a microgrid setup } \\
\text { i.e. they can sell the excess energy. }\end{array}$ \\
\hline Power Loss & $\begin{array}{l}\text { - High value of T\&D loss } \\
\text { - Power loss is also due to inter-state and intra-state transmission loss. }\end{array}$ & $\begin{array}{l}\text { - Microgrid makes the installation of energy sources } \\
\text { within the city and reduces the T\&D loss to a } \\
\text { greater extent. }\end{array}$ \\
\hline
\end{tabular}

Smart grid is an alternative which could help in reduction of T\&D losses [22]. However, the up-gradation of current transmission and distribution system into smart grid is a time taking and tedious task. The shortcomings in the T\&D system from the point of view of smart city can be overcome by the implantation of microgrid as it provides an instant solution to the problems of T\&D system. It acts as a panacea for various problems based on parameters mentioned in Table 3. The microgrid has already proved its benefits for the electricity supply in Indian villages $[23,24]$ and thus now its advantage by implementing in smart city is analyzed in terms of system losses minimization and reliability enhancement.

\section{Results and Discussions}

In the previous sections, economic and technical aspects related to amalgamation of microgrid in a smart city set up were discussed. It can be concluded from the above discussions that system losses in present electrical infrastructure of the state of
Uttar Pradesh were on higher side, immediate action is the need of the hour as smart city and robust /reliable electricity infrastructure work hand in glove i.e. it would be difficult to make city smart without a robust/reliable electrical infrastructure. In this paper impact of deployment of microgrid in a smart city were measured in terms of loss reduction and enhancement of reliability. The results are discussed for the city of Rampur located in the state of Uttar Pradesh as losses here is highest among all other smart cities of the state. The radial distribution network of the Rampur city is shown in Fig. 9. It has 11 number of $11 \mathrm{kV}$ buses which are fed from the 132/ $33 \mathrm{kV}$ Panwadiya substation. The detail of the distribution network is given in Table 4 (http://pvvnl.org/technical.html). The microgrid is formed at feeder F2, F3 and F4 of bus 5 of the network. An equivalent conventional generation model for point of common coupling (PCC) is considered as shown in Fig. 10 [16]. A total of 3.5 MW of supply from the different distributed generators (DGs) of microgrid as given in Table 5 is considered for the assessment of losses and reliability of the distribution network.

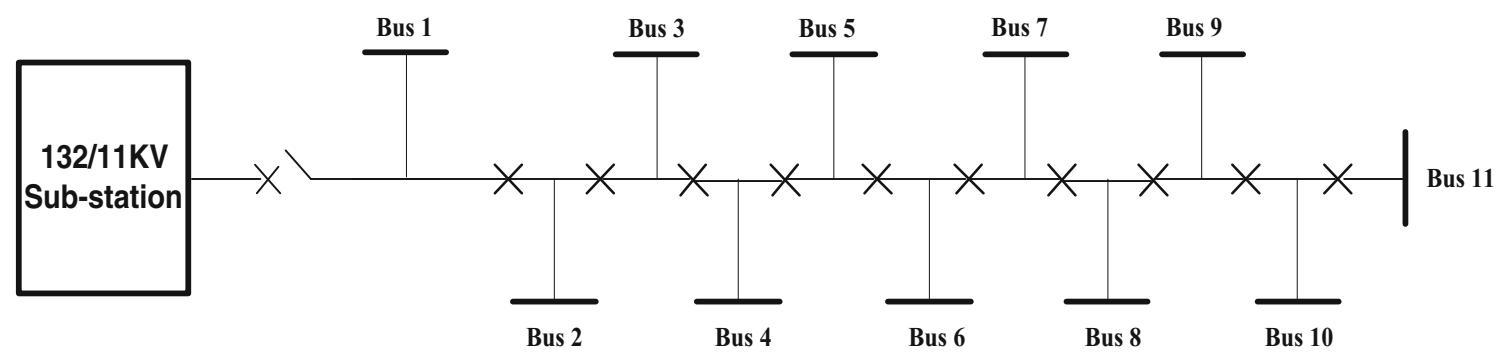

Fig. 9 Single line representation of electrical distribution network of Rampur 
Table 4 Bus details of distribution network of Rampur

\begin{tabular}{llll}
\hline Bus No. & Name of 33/11 KV Sub-Station & Average Load (MW) & Peak Load (MW) \\
\hline 1 & Panwadiya & 5.1 & 6.38 \\
2 & Ambedkar Park & 2.55 & 3.19 \\
3 & Civil Line & 7.65 & 9.56 \\
4 & Ajitpur & 5.75 & 6.38 \\
5 & Raza Inter College & 6.54 & 8.29 \\
6 & Dungarpur & 7.65 & 9.56 \\
7 & Qila & 6.75 & 8.29 \\
8 & Bilaspur Gate & 5.25 & 6.38 \\
9 & Shahbad Gate & 9.18 & 11.48 \\
10 & Pahari Gate & 6.63 & 8.29 \\
11 & Nawab Gate & 3.25 & 3.83 \\
\hline
\end{tabular}

\section{Distribution Loss Assessment}

The load flow solutions of the considered network shows that there is a considerable decrease of $6.93 \%$ and $6.76 \%$ in system real power and reactive power losses respectively with the deployment of microgrid in the distribution network as compared to base case (without microgrid) as shown in Table 6 .

Thus, the overall system losses reduced with the deployment of microgrid in the distribution network thereby enhancing its overall efficiency which is a key technical aspect considered in the context of electrical infrastructure of smart city.

\section{Reliability Assessment}

Reliability assessment of a power distribution network is a measure of the adequacy of electricity supply available to the customers of different load points. The

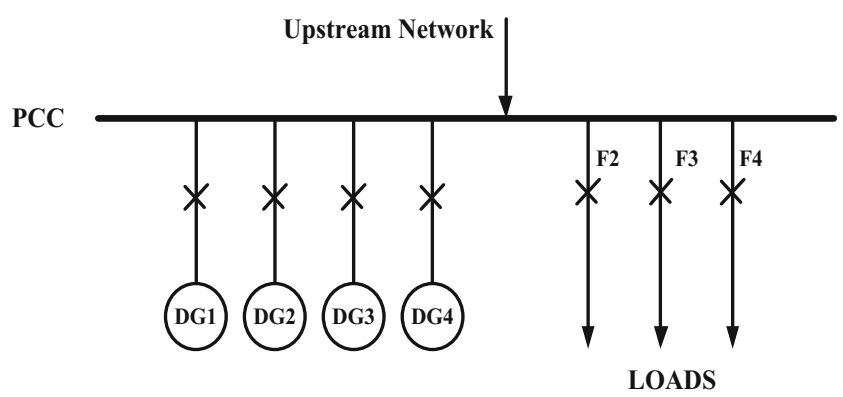

Fig. 10 Schematic diagram of microgrid structure with PCC equivalence

Table 5 Details of distributed generators

\begin{tabular}{lllll}
\hline Generator & DG1 & DG2 & DG3 & DG4 \\
\hline Type & Battery & PV & Battery & PV \\
Rating $(\mathrm{kW})$ & 300 & 1500 & 200 & 1500 \\
\hline
\end{tabular}

commonly used load point indices are average failure rate $\left(\lambda_{\mathrm{i}}\right)$, average duration of outage $\left(\mathrm{r}_{\mathrm{i}}\right)$ and average annual outage time $\left(\mathrm{U}_{\mathrm{i}}\right)[25,26]$. Since, reliable supply is one of the important requirements of a smart city, therefore these indices are evaluated for various load points of Rampur city which helps in assessing its distribution network performance. The configuration of the loads connected to different feeders of bus 5 of the distribution network of Rampur is shown in Fig.11. The load data for the reliability assessment of these loads are given in Appendix (Table 9) with an approximate number of consumers. The distribution transformers and line components failure rates are assumed to be constant. Their repair and switching times are also assumed to be constant. The switching actions are assumed to be absolutely reliable. Considering the microgrid is formed at feeder F2, F3 and F4, these microgrids formed will be redundant to other feeders as it will not affect the reliability of the loads connected to these feeders. Therefore, the reliability studies for the load connected to feeders F2, F3 and F4 of bus 5 are performed for the base case (without microgrid) and with the microgrid present and the results are shown in Table 7. It is observed that with the deployment of microgrid, the average failure rate and average outage duration to the load points of feeders F2, F3 and F4 are decreased and consequently a significant decrease in annual average outage duration is achieved, thereby enhancing the distribution network reliability.

Table 6 System losses for different ratings of generators in microgrid

\begin{tabular}{lccl}
\hline Losses & Base Case & With Microgrid & Percentage Decrease \\
\hline $\mathrm{P}_{\mathrm{L}}(\mathrm{kW})$ & 1169 & 1088 & $6.93 \%$ \\
$\mathrm{Q}_{\mathrm{L}}(\mathrm{kVAR})$ & 429 & 399 & $6.76 \%$ \\
\hline
\end{tabular}




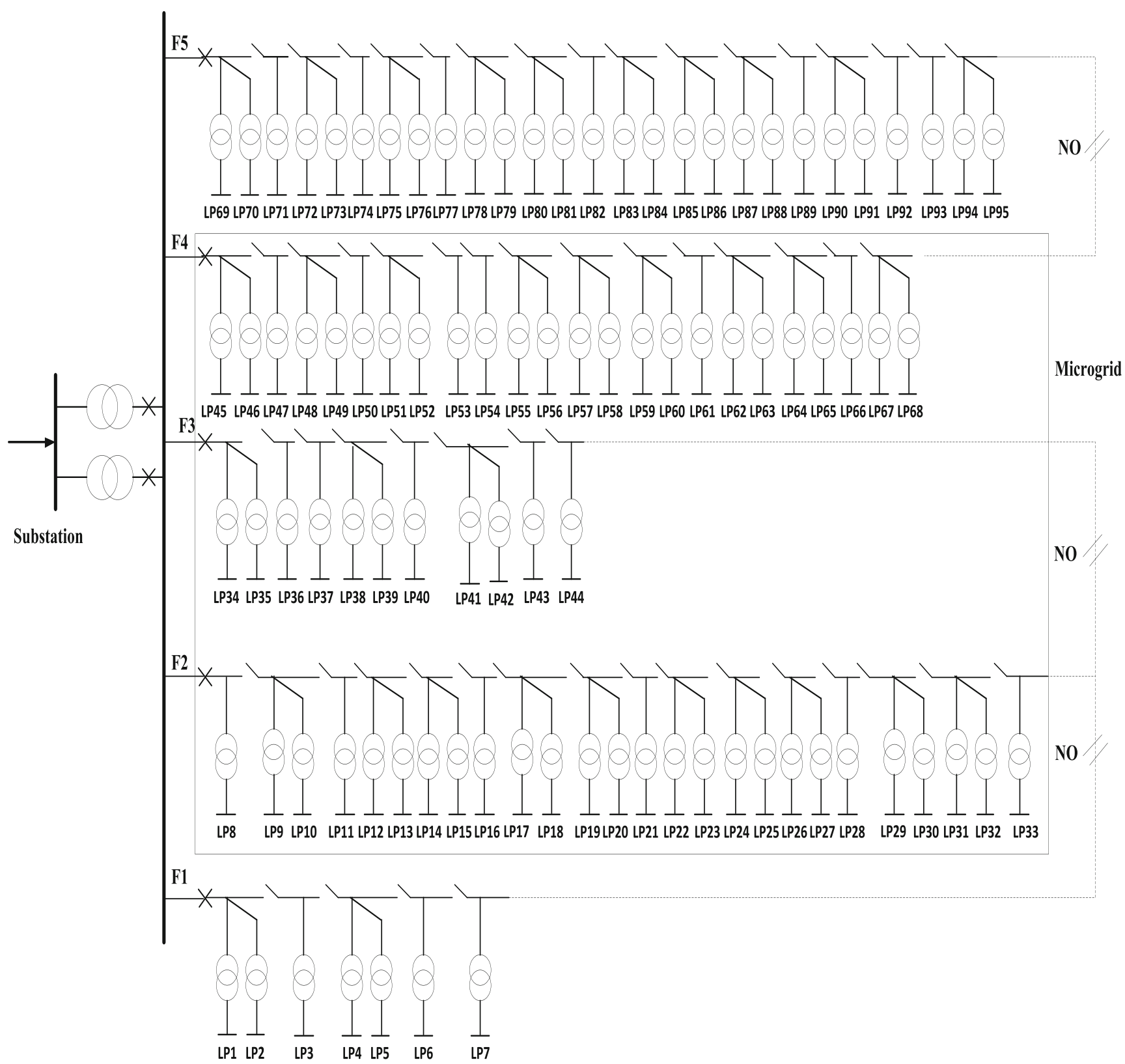

Fig. 11 Details of bus 5 of electrical distribution network of Rampur

The reliability assessment of the distribution network is also done on the basis of evaluation of several system reliability indices such as system average interruption failure index (SAIFI), system average interruption duration index (SAIDI), customer average interruption duration index (CAIDI), energy not supplied (ENS) and average energy not supplied (AENS) $[25,26]$. These indices are most common and are widely used to assess the distribution network performance. SAIFI, SAIDI and CAIDI are customer oriented indices while ENS and AENS are load and energy oriented indices. SAIFI and SAIDI are a measure of system interruption frequency and duration respectively while CAIDI is the measure of the duration of interruption of electricity supply to a customer. ENS and AENS, being the load and energy oriented indices, are a measure of energy not supplied by the system. These indices are briefly discussed below [26].

System Average Interruption Failure Index (SAIFI) SAIFI is the most common reliability index to measure the performance of system interruption. It is the average of number of times a customer experiences an outage during specified period of time and is given as:

$S A I F I=\frac{\sum \lambda_{i} N_{i}}{\sum N i}$

where $\mathrm{N}_{\mathrm{i}}$ is the number of customers at load point-i. 
Table 7 Reliability Indices for different load points

\begin{tabular}{|c|c|c|c|c|c|c|c|}
\hline \multirow[t]{2}{*}{ Feeder No. } & \multirow[t]{2}{*}{ Load Point } & \multicolumn{3}{|c|}{ Base Case } & \multicolumn{3}{|c|}{ With Microgrid } \\
\hline & & $\lambda_{i}(f / y r)$ & $\mathrm{r}_{\mathrm{i}}(\mathrm{hr})$ & $\mathrm{U}_{\mathrm{i}}(\mathrm{hr} /$ year) & $\lambda_{\mathrm{i}}(\mathrm{f} / \mathrm{yr})$ & $\mathrm{r}_{\mathrm{i}}(\mathrm{hr})$ & $\mathrm{U}_{\mathrm{i}}$ (hr/year) \\
\hline \multirow[t]{26}{*}{$\mathrm{F} 2$} & LP8 & 0.781 & 9.23 & 7.21 & 0.771 & 8.40 & 6.48 \\
\hline & LP9 & 0.785 & 9.232 & 7.25 & 0.773 & 8.37 & 6.47 \\
\hline & LP10 & 0.785 & 9.232 & 7.25 & 0.773 & 8.37 & 6.47 \\
\hline & LP11 & 0.783 & 9.234 & 7.23 & 0.773 & 8.37 & 6.47 \\
\hline & LP12 & 0.781 & 9.23 & 7.21 & 0.772 & 8.39 & 6.48 \\
\hline & LP13 & 0.781 & 9.23 & 7.21 & 0.771 & 8.40 & 6.48 \\
\hline & LP14 & 0.783 & 9.234 & 7.23 & 0.771 & 8.40 & 6.48 \\
\hline & LP15 & 0.783 & 9.234 & 7.23 & 0.772 & 8.39 & 6.48 \\
\hline & LP16 & 0.781 & 9.23 & 7.21 & 0.772 & 8.39 & 6.48 \\
\hline & LP17 & 0.772 & 9.23 & 7.13 & 0.771 & 8.40 & 6.48 \\
\hline & LP18 & 0.772 & 9.39 & 7.25 & 0.765 & 8.45 & 6.46 \\
\hline & LP19 & 0.772 & 9.39 & 7.25 & 0.765 & 8.45 & 6.46 \\
\hline & LP20 & 0.772 & 9.39 & 7.25 & 0.765 & 8.45 & 6.46 \\
\hline & LP21 & 0.781 & 9.23 & 7.21 & 0.771 & 8.40 & 6.48 \\
\hline & LP22 & 0.772 & 9.39 & 7.25 & 0.771 & 8.40 & 6.48 \\
\hline & LP23 & 0.772 & 9.39 & 7.25 & 0.765 & 8.45 & 6.46 \\
\hline & LP24 & 0.781 & 9.23 & 7.21 & 0.771 & 8.40 & 6.48 \\
\hline & LP25 & 0.781 & 9.23 & 7.21 & 0.771 & 8.40 & 6.48 \\
\hline & LP26 & 0.783 & 9.234 & 7.23 & 0.772 & 8.39 & 6.48 \\
\hline & LP27 & 0.783 & 9.234 & 7.23 & 0.772 & 8.39 & 6.48 \\
\hline & LP28 & 0.781 & 9.23 & 7.21 & 0.771 & 8.40 & 6.48 \\
\hline & LP29 & 0.783 & 9.234 & 7.23 & 0.771 & 8.40 & 6.48 \\
\hline & LP30 & 0.783 & 9.234 & 7.23 & 0.772 & 8.40 & 6.48 \\
\hline & LP31 & 0.781 & 9.23 & 7.21 & 0.771 & 8.40 & 6.48 \\
\hline & LP32 & 0.781 & 9.23 & 7.21 & 0.771 & 8.40 & 6.48 \\
\hline & LP33 & 0.785 & 9.232 & 7.25 & 0.771 & 8.40 & 6.48 \\
\hline \multirow[t]{11}{*}{$\mathrm{F} 3$} & LP34 & 0.695 & 10.53 & 7.32 & 0.667 & 9.41 & 6.28 \\
\hline & LP35 & 0.695 & 10.53 & 7.32 & 0.667 & 9.41 & 6.28 \\
\hline & LP36 & 0.698 & 10.51 & 7.34 & 0.671 & 9.37 & 6.29 \\
\hline & LP37 & 0.695 & 10.53 & 7.32 & 0.667 & 9.41 & 6.28 \\
\hline & LP38 & 0.698 & 10.51 & 7.34 & 0.671 & 9.37 & 6.29 \\
\hline & LP39 & 0.698 & 10.51 & 7.34 & 0.671 & 9.37 & 6.29 \\
\hline & LP40 & 0.695 & 10.53 & 7.32 & 0.667 & 9.41 & 6.28 \\
\hline & LP41 & 0.691 & 10.57 & 7.30 & 0.665 & 9.44 & 6.28 \\
\hline & LP42 & 0.691 & 10.57 & 7.30 & 0.665 & 9.44 & 6.28 \\
\hline & LP43 & 0.691 & 10.57 & 7.30 & 0.665 & 9.44 & 6.28 \\
\hline & LP44 & 0.695 & 10.53 & 7.32 & 0.667 & 3.41 & 2.27 \\
\hline \multirow[t]{24}{*}{$\mathrm{F} 4$} & LP45 & 0.783 & 9.234 & 7.23 & 0.772 & 9.39 & 6.25 \\
\hline & LP46 & 0.783 & 9.234 & 7.23 & 0.772 & 9.39 & 6.25 \\
\hline & LP47 & 0.783 & 9.234 & 7.23 & 0.772 & 9.39 & 6.25 \\
\hline & LP48 & 0.785 & 9.232 & 7.25 & 0.773 & 9.37 & 6.24 \\
\hline & LP49 & 0.785 & 9.232 & 7.25 & 0.773 & 9.37 & 6.24 \\
\hline & LP50 & 0.783 & 9.234 & 7.23 & 0.772 & 9.39 & 6.25 \\
\hline & LP51 & 0.778 & 9.31 & 7.24 & 0.766 & 9.44 & 6.23 \\
\hline & LP52 & 0.778 & 9.31 & 7.24 & 0.766 & 9.44 & 6.23 \\
\hline & LP53 & 0.778 & 9.31 & 7.24 & 0.766 & 9.44 & 6.23 \\
\hline & LP54 & 0.785 & 9.232 & 7.25 & 0.773 & 9.37 & 6.24 \\
\hline & LP55 & 0.783 & 9.234 & 7.23 & 0.772 & 9.39 & 6.25 \\
\hline & LP56 & 0.783 & 9.234 & 7.23 & 0.772 & 9.39 & 6.25 \\
\hline & LP57 & 0.783 & 9.234 & 7.23 & 0.772 & 9.39 & 6.25 \\
\hline & LP58 & 0.783 & 9.234 & 7.23 & 0.772 & 9.39 & 6.25 \\
\hline & LP59 & 0.785 & 9.232 & 7.25 & 0.773 & 9.37 & 6.24 \\
\hline & LP60 & 0.785 & 9.232 & 7.25 & 0.773 & 9.37 & 6.24 \\
\hline & LP61 & 0.785 & 9.232 & 7.25 & 0.773 & 9.37 & 6.24 \\
\hline & LP62 & 0.783 & 9.234 & 7.23 & 0.772 & 9.39 & 6.25 \\
\hline & LP63 & 0.783 & 9.234 & 7.23 & 0.772 & 9.39 & 6.25 \\
\hline & LP64 & 0.773 & 9.37 & 7.24 & 0.762 & 9.47 & 6.22 \\
\hline & LP65 & 0.773 & 9.37 & 7.24 & 0.762 & 9.47 & 6.22 \\
\hline & LP66 & 0.773 & 9.37 & 7.24 & 0.762 & 9.47 & 6.22 \\
\hline & LP67 & 0.778 & 9.31 & 7.24 & 0.766 & 9.44 & 6.23 \\
\hline & LP68 & 0.778 & 9.31 & 7.24 & 0.766 & 9.44 & 7.23 \\
\hline
\end{tabular}


Table 8 Reliability indices of the distribution system

\begin{tabular}{lccccr}
\hline Reliability Indices & SAIFI & SAIDI & CAIDI & ENS & AENS \\
\hline Base Case & 0.768 & 7.255 & 9.443 & 40,333 & 10.696 \\
With Microgrid & 0.759 & 6.558 & 8.635 & 37,035 & 9.821 \\
\hline
\end{tabular}

System Average Interruption Duration Index (SAIDI) SAIDI is the measure of performance of the system for sustained interruption. It is measured in terms of the total duration of interruption for the average customers over a specified time period. It is expressed as:

$S A I D I=\frac{\sum U_{i} N_{i}}{\sum N i}$

Customer Average Interruption Duration Index (CAIDI) From customer's point of view, CAIDI is one of the important index to measure the reliability of supply. It is the ratio of total duration of customer interruptions and total number of customer interruptions and is expressed as:

$C A I D I=\frac{\sum U_{i} N_{i}}{\sum \lambda_{i} N i}$

Energy Not Supplied (ENS) ENS is the measure of energy not supplied by the system to the customer connected at load point-i and is given as:

$E N S=\sum L_{i} U_{i}$

where $L_{i}$ is the average load connected to load point-i.

Average Energy Not Supplied (AENS) AENS is the average energy not supplied by the system to the customer connected at load point-i over a specified period of time and is given as:

$A E N S=\frac{\sum L_{i} U_{i}}{\sum N i}$

The values of the reliability indices obtained after the deployment of microgrids are much better than those obtained without the deployment of microgrids, thereby reducing the average outage time of power supply and enhancing the reliability. From Table 8, it can be observed that though there is not a significant change in the value of SAIFI from the base case but there is a considerable change in the values of SAIDI and CAIDI. An overall improvement of $9.61 \%$ and $8.56 \%$ in the values of SAIDI and CAIDI respectively are observed as compared to $1.15 \%$ in the value of SAIFI. Similarly, an improvement of $8.12 \%$ in the value of ENS and AENS indices were observed with the application of microgrid. The improvement in these reliability indices values results in less duration of unavailability of electricity supply to the consumers of different load points, thereby enhancing the overall reliability of the distribution system.

\section{Conclusions}

In this work technical and economic aspects of deployment of microgrids for meeting the energy requirements of smart city were presented. A detailed assessment of implementing microgrid and its impact on distribution network performance was presented. The assessment was mainly done by taking into account the provisions of smart city especially in terms of power requirement. The main objective of the work was to strengthen the existing T\&D system by reducing the system loss along with increasing its reliability. Various load point and system/customer oriented indices such as failure rate, outage duration, annual average outage duration, SAIFI, SAIDI, CAIDI, ENS and AENS are evaluated to analyze the distribution network performance. The analysis was done for the city of Rampur which has been shortlisted by Government of India for transformation into smart city. The results are analyzed on the basis of two cases 1) Base case (without the deployment of microgrids) 2) with the deployment of microgrids in the distribution network. The result obtained after the deployment of microgrids in distribution network shows a considerable reduction in distribution losses and improved value of reliability indices as compared to those obtained for the base case. Although, there is no significant impact of the microgrid implementation of considered rating on the value of SAIFI due to less improvement in failure rate, a significant improvement in the values of SAIDI, CAIDI, ENS and AENS are observed. The improved values of reliability indices obtained shows an encouraging trend in overall enhancement of system reliability, henceforth it is highly recommended to implement microgrid into distribution network in order to meet the provisions of smart city in terms of power requirement.

Acknowledgements We would like to thank the following individuals who were essential to the completion of this work: Mr. Tausif Hussain, Director, Lambent Engineering, for his assistance in data collection of Rampur. The professors of the University of Jamia Millia Islamia who provided additional consultation in the formulation of our research analysis.

\section{Compliance with Ethical Standards}

Conflict of Interest The authors declare that they have no conflict of interest. 


\section{Appendix}

Table 9 Details of load points of different feeders at bus 5 of Rampur

\begin{tabular}{|c|c|c|c|c|c|c|c|c|c|c|c|}
\hline \multicolumn{12}{|l|}{ Feeder 1} \\
\hline Load Point & LP1 & LP2 & LP3 & LP4 & LP5 & LP6 & LP7 & & & & \\
\hline No. of Consumers & 25 & 20 & 31 & 87 & 1 & 1 & 1 & & & & \\
\hline Average Load (kW) & 37.93 & 25.02 & 37.34 & 86.59 & 38.73 & 2.98 & 9.53 & & & & \\
\hline Peak Load (kW) & 63.75 & 40.16 & 63.75 & 90.75 & 40.78 & 6.38 & 15.94 & & & & \\
\hline \multicolumn{12}{|l|}{ Feeder 2} \\
\hline Load Point & LP8 & LP9 & LP10 & LP11 & LP12 & LP13 & LP14 & LP15 & LP16 & & \\
\hline No. of Consumers & 17 & 72 & 24 & 31 & 16 & 1 & 1 & 29 & 30 & & \\
\hline Average Load (kW) & 31.38 & 219.26 & 34.96 & 14.30 & 29.99 & 7.75 & 7.75 & 51.04 & 19.86 & & \\
\hline Peak Load (kW) & 63.75 & 225.38 & 63.75 & 40.23 & 42.33 & 15.94 & 15.94 & 63.75 & 35.43 & & \\
\hline Load Point & LP17 & LP18 & LP19 & LP20 & LP21 & LP22 & LP23 & LP24 & LP25 & & \\
\hline No. of Consumers & 26 & 54 & 31 & 19 & 21 & 60 & 13 & 21 & 28 & & \\
\hline Average Load (kW) & 51.04 & 157.10 & 80.04 & 41.91 & 25.22 & 134.06 & 35.55 & 23.04 & 31.38 & & \\
\hline Peak Load (kW) & 63.75 & 170.35 & 85.35 & 63.75 & 40.23 & 159.38 & 63.75 & 40.23 & 63.75 & & \\
\hline Load Point & LP26 & LP27 & LP28 & LP29 & LP30 & LP31 & LP32 & LP33 & & & \\
\hline No. of Consumers & 33 & 107 & 32 & 13 & 24 & 14 & 50 & 9 & & & \\
\hline Average Load (kW) & 134.06 & 35.35 & 28.40 & 31.18 & 134.06 & 37.34 & 157.50 & 19.46 & & & \\
\hline Peak Load (kW) & 150.25 & 55.35 & 55.35 & 55.35 & 150.25 & 63.75 & 170.35 & 40.23 & & & \\
\hline \multicolumn{12}{|l|}{ Feeder 3} \\
\hline Load Point & LP34 & LP35 & LP36 & LP37 & LP38 & LP39 & LP40 & LP41 & LP42 & LP43 & LP44 \\
\hline No. of Consumers & 83 & 19 & 15 & 30 & 55 & 52 & 60 & 22 & 28 & 26 & 107 \\
\hline Average Load (kW) & 139.82 & 22.64 & 1.59 & 21.05 & 13.31 & 13.90 & 40.91 & 21.25 & 26.61 & 18.27 & 98.31 \\
\hline Peak Load (kW) & 159.38 & 63.75 & 11.23 & 40.23 & 40.23 & 40.23 & 63.75 & 40.23 & 40.23 & 40.23 & 159.38 \\
\hline \multicolumn{12}{|l|}{ Feeder 4} \\
\hline Load Point & LP45 & LP46 & LP47 & LP48 & LP49 & LP50 & LP51 & LP52 & & & \\
\hline No. of Consumers & 5 & 25 & 12 & 4 & 11 & 30 & 32 & 84 & & & \\
\hline Average Load (kW) & 8.94 & 24.43 & 31.38 & 8.14 & 20.66 & 5.36 & 25.82 & 193.44 & & & \\
\hline Peak Load (kW) & 15.94 & 40.23 & 63.75 & 15.94 & 40.12 & 15.94 & 40.12 & 250.25 & & & \\
\hline Load Point & LP53 & LP54 & LP55 & LP56 & LP57 & LP58 & LP59 & LP60 & & & \\
\hline No. of Consumers & 25 & 96 & 218 & 119 & 34 & 15 & 62 & 117 & & & \\
\hline Average Load (kW) & 1.39 & 158.89 & 122.74 & 143.20 & 92.95 & 19.07 & 151.74 & 110.62 & & & \\
\hline Peak Load (kW) & 10.23 & 170.25 & 255.00 & 159.38 & 159.38 & 25.30 & 200.25 & 159.38 & & & \\
\hline Load Point & LP61 & LP62 & LP63 & LP64 & LP65 & LP66 & LP67 & LP68 & & & \\
\hline No. of Consumers & 75 & 8 & 33 & 4 & 58 & 20 & 9 & 8 & & & \\
\hline Average Load (kW) & 41.31 & 8.94 & 28.60 & 7.75 & 38.53 & 20.85 & 11.12 & 19.66 & & & \\
\hline Peak Load (kW) & 63.75 & 15.94 & 63.75 & 15.94 & 63.75 & 63.75 & 25.25 & 35.21 & & & \\
\hline \multicolumn{12}{|l|}{ Feeder 5} \\
\hline Load Point & LP69 & LP70 & LP71 & LP72 & LP73 & LP74 & LP75 & LP76 & LP77 & & \\
\hline No. of Consumers & 35 & 53 & 39 & 6 & 30 & 82 & 16 & 24 & 1 & & \\
\hline Average Load (kW) & 25.42 & 232.77 & 155.31 & 21.25 & 16.88 & 129.69 & 11.12 & 56.80 & 17.08 & & \\
\hline Peak Load (kW) & 35.21 & 255.00 & 170.26 & 63.75 & 40.21 & 159.38 & 40.21 & 63.75 & 20.19 & & \\
\hline Load Point & LP78 & LP79 & LP80 & LP81 & LP82 & LP83 & LP84 & LP85 & LP86 & & \\
\hline No. of Consumers & 26 & 34 & 141 & 24 & 44 & 32 & 67 & 219 & 14 & & \\
\hline Average Load $(\mathrm{kW})$ & 23.63 & 22.05 & 205.76 & 20.46 & 43.30 & 7.55 & 107.45 & 374.38 & 11.32 & & \\
\hline Peak Load (kW) & 63.75 & 63.75 & 159.38 & 63.75 & 63.75 & 15.62 & 155.00 & 400.00 & 25.25 & & \\
\hline Load Point & LP87 & LP88 & LP89 & LP90 & LP91 & LP92 & LP93 & LP94 & LP95 & & \\
\hline No. of Consumers & 10 & 92 & 28 & 9 & 25 & 23 & 127 & 14 & 13 & & \\
\hline Average Load (kW) & 18.67 & 128.70 & 25.82 & 35.15 & 31.38 & 42.70 & 205.36 & 18.87 & 49.85 & & \\
\hline Peak Load (kW) & 40.12 & 170.00 & 63.75 & 63.75 & 63.75 & 63.75 & 225.00 & 4025.00 & 63.75 & & \\
\hline
\end{tabular}




\section{References}

1. Batty M, Axhausen KW, Giannotti F et al (2012) Smart cities of the future. Eur Phys J Special Topics 214(1):481-518

2. Coelho VN et al (2017) A communitarian microgrid storage planning system inside the scope of a smart city. Appl Energy 201: $371-381$

3. Jin X (2015) "Analysis of microgrid comprehensive benefits and evaluation of its economy", In Proceedings of 10th International Conference on Advances in Power System Control, Operation \& Management (APSCOM 2015), Hong Kong, China, pp 1-4

4. Liang C, Shahidehpour M (2014) DC microgrids: economic operation and enhancement of resilience by hierarchical control. IEEE Trans Smart Grid 5(5):2517-2526

5. Morris GY, Abbey C, Won S, Joós G (2012) "Evaluation of the costs and benefits of microgrids with consideration of services beyond energy supply". In Proceedings of IEEE Power and Energy Society General Meeting, San Diego, USA, pp 1-9

6. Liu N et al (2015) A heuristic operation strategy for commercial building microgrids containing EVs and PV system. IEEE Trans Ind Electron 62(4):2560-2570

7. Hernández L, Baladron C, Aguiar JM, Massana J (2014) A survey on electric power demand forecasting: Future trends in smart grids, microgrids and smart buildings. IEEE Communication Surveys \& Tutorials 16(3):1460-1495, 3rd Quart

8. Allan RN et al (1991) A reliability test system for educational purposes-Basic distribution system data and results. IEEE Transactions on Power Systems 6(2):813-820

9. Costa PM, Matos MA (2005) "Reliability of distribution networks with microgrids", In Proceedings of IEEE International Conference on Power Tech, Russia, pp 1-7

10. Puianu M, Flangea RO, Arghira N, Iliescu SS (2017) "Microgrid simulation for smart city", In Proceedings of 9th IEEE International Conference on Intelligent Data Acquisition Advanced Computing Systems, Technology and Applications (IDAACS), Bucharest, Romania, pp 21-23

11. Bae IS, Kim JO (2008) Reliability evaluation of customers in a microgrid. IEEE Trans Power Syst 23(3):1416-1422

12. Mehta R (2019) "A microgrid case study for ensuring reliable power for commercial and industrial sites", In Proceedings of IEEE PES GTD Grand International Conference and Exposition Asia (GTD Asia), Bangkok, Thailand, pp 594-598, 19-23

13. Ruan C et al (2018) "Reliability Calculation Based on Honeycomb Distribution Grid", In Proceedings of IEEE International Power Electronics and Application Conference and Exposition (PEAC), Shenzen, China, pp 1-6, 4-7
14. Wu X et al (2019) Microgrid planning considering the resilience against contingencies. IET Gener Transm Distrib 13(16):3534 3548

15. Atwa YM, El-Saadany EF (2009) Reliability evaluation for distribution system with renewable distributed generation during islanded mode of operation. IEEE Trans Power Syst 24(2):572-581

16. Wang S, Li Z, Wu L, Shahidehpour M, Li Z (2013) New metrics for assessing the reliability and economics of microgrids in distribution system. IEEE Trans Power Syst 28(3):2852-2861

17. Albino V, Berardi U, Dangelico RM (2015) Smart cities: definitions, dimensions, performance, and initiatives. J Urban Technol 22(1):3-21

18. Cocchia A (2014) Smart and digital city: a systematic literature review. In: Dameri RP, Rosenthal-Sabroux C (eds) Smart City. Springer-Verlag, New York, pp 13-43

19. Nguyen MY, Yoon YT (2014) A comparison of microgrid topologies considering both market operations and reliability. Electr Power Components Syst 42(6):585-594

20. Hatziargyriou ND, Anastasiadis AG, Vasiljevska J, Tsikalakis AG (2009) "Quantification of economic, environmental and operational benefits of microgrids", In Proceedings of IEEE Bucharest Power Tech Conference, Bucharest, Romania, pp 1-8

21. Mam M, Joseph A, Singh A, Alam MP, Popli S (2014) A case study on issues and challenges faced during strengthening of a distribution unit by reducing aggregate technical and commercial loss. Int $\mathrm{J}$ Electr Electron Res (IJEER) 2(1):36-40

22. Masera M, Bompard EF, Profumo F, Hadjsaid N (2018) "Smart (Electricity) Grids for Smart Cities: Assessing Roles and Societal Impacts", In Proceedings of IEEE pp 613-625, Vol. 106, No. 4

23. Sandwell $P$ et al (2016) Analysis of energy access and impact of modern energy sources in unelectrified villages in Uttar Pradesh. Energy for Sustainable Development 35:67-79

24. Sher F, Kawai A, Gulec F, Sadiq H (2019) Sustainable energy saving alternatives in small buildings. Sustain Energ Technol Assess 32:92-99

25. Numminen S, Lund PD (2019) Evaluation of the reliability of solar micro-grids in emerging markets - issues and solutions. Energy Sustain Dev 48:34-42

26. Bourezg A, Meglouli H (2015) Reliability assessment of power distribution systems using disjoint path-set algorithm. J Ind Eng Int 11(1):45-57

Publisher's Note Springer Nature remains neutral with regard to jurisdictional claims in published maps and institutional affiliations. 